\title{
Endoscopic retrieval of a migrated esophageal stent in the cecum
}
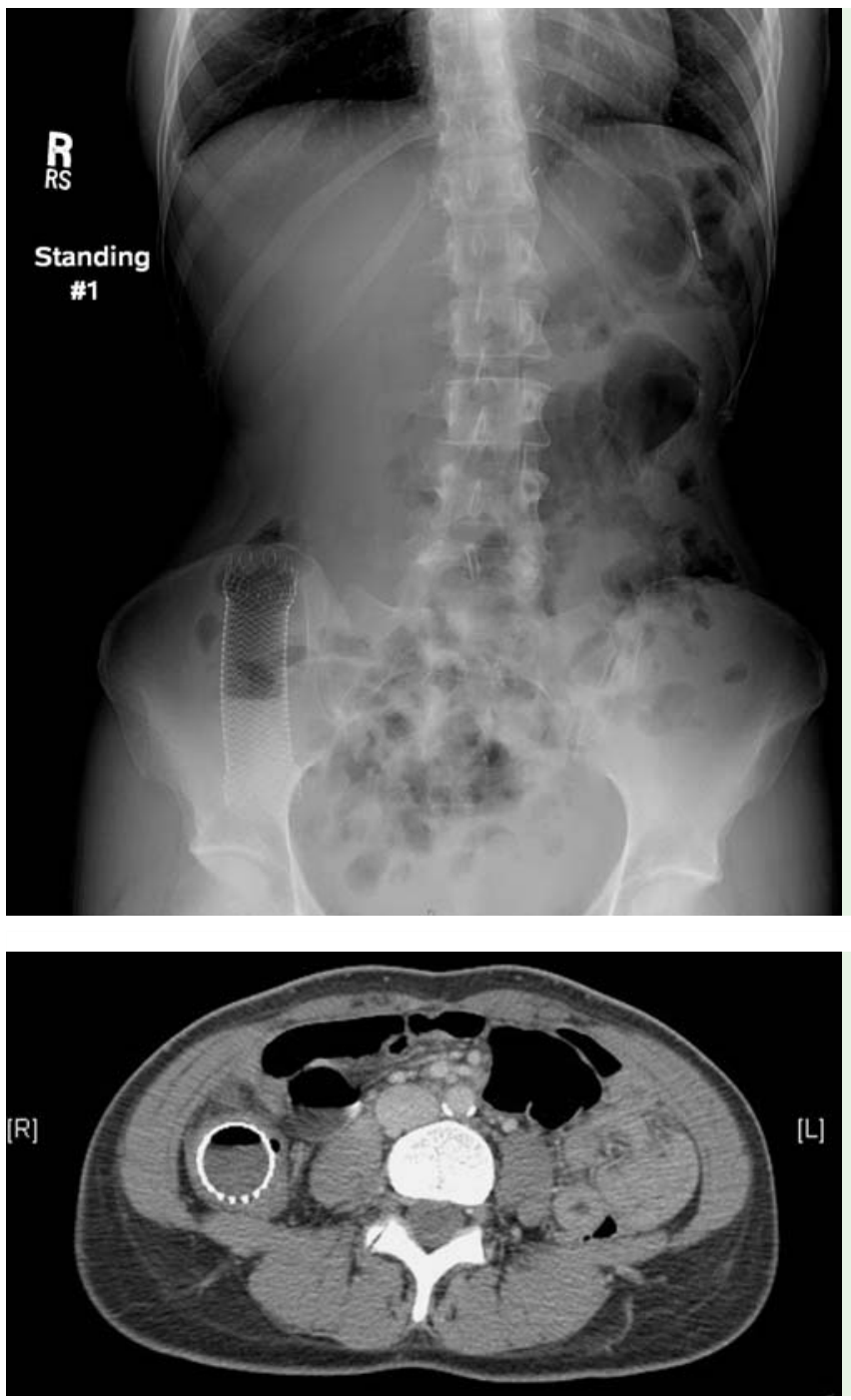

A 38-year-old woman with a history of total gastrectomy in 2006 for adenocarcinoma presented with complaints of severe right-sided abdominal pain and dysphagia. The patient had experienced progressive intolerance to solid foods and a 50-lb weight loss over 1 year. Work-up at an outside institution revealed recurrent cancer at the esophago-enteric anastomosis, and a $23 \mathrm{~mm} \times 100 \mathrm{~mm}$ Wallflex partially covered esophageal stent (Boston Scientific, Natick, Massachusetts, USA) was placed at that time. The patient noted rapid recurrence in dysphagia and concomitant abdominal discomfort after 2 days.

An abdominal radiograph showed the stent in the right lower quadrant with no dilated loops of bowel or free intraperitoneal air ( Fig. 1).
Fig. 1 Upright abdominal plain film showing stent in right lower quadrant; no dilated loops of bowel or free intraperitoneal air is seen.

Fig. 2 Abdominal computed tomography showing the metallic stent within the cecum and ascending colon.

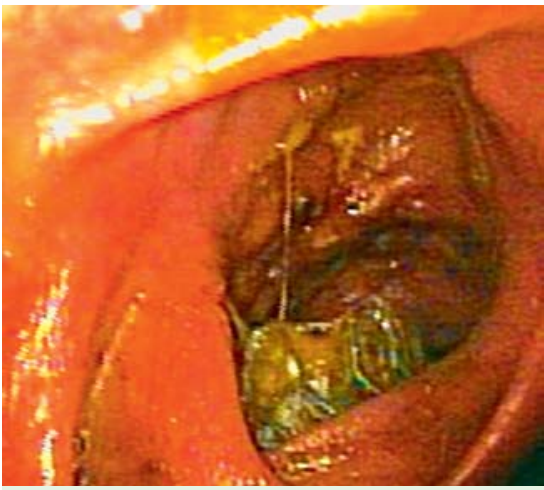

Fig. 3 Wallflex stent in the ascending colon.

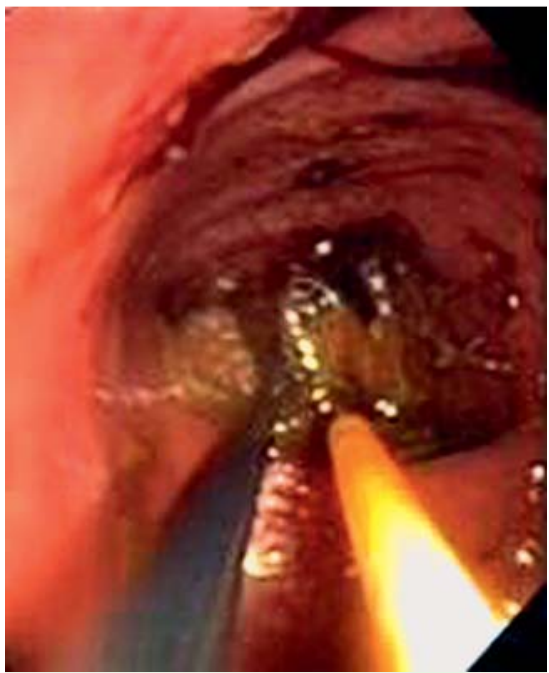

Fig. 4 A combination of rat tooth forceps (black) and biopsy forceps (orange) is used to grab opposite ends of the stent to allow for better control.

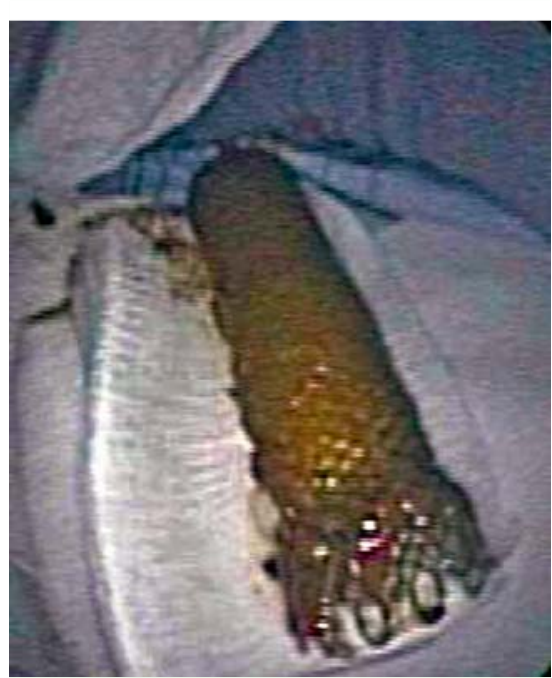

Fig. 5 Retrieved Wallflex stent.
An abdominal computed tomography scan showed the stent in the ascending colon ( Fig. 2).

After 72 hours of conservative management, which failed, the decision was made to pursue endoscopic retrieval.

Using an Olympus CF-H180 colonoscope (Olympus Corp., Tokyo, Japan), we attempted to place a snare around the stent in the ascending colon ( $\nabla$ Fig. 3 ) but could not encase it circumferentially as the distal end flared to $28 \mathrm{~mm}$.

A rat tooth forceps was then utilized to draw the stent into the left colon. The stent could not be withdrawn further due to sharp turns in the descending colon. A double-channel upper endoscope (Olympus GIF-2TQ160) was advanced, and a rat tooth and biopsy forceps were used 
simultaneously to grab opposite ends of the stent ( $\bullet$ Fig. 4 ).

After a total of 70 minutes of maneuvering, the stent was withdrawn from the rectum ( $\bullet$ Fig.5), and the patient recovered without issue.

Placement of self-expandable stents is an accepted option for malignant esophageal obstruction after gastric surgery [1]. Migration is an uncommon, but known, complication of esophageal stent placement [2]. This case illustrates an extremely rare occurrence of a $100-\mathrm{mm}$ long stent migrating through the small intestine into the colon, and highlights a successful endoscopic retrieval technique using a combination of endoscopic tools.

Competing interests: None

Endoscopy_UCTN_Code_CPL_1AH_2AD

\section{B. Shah, K. Jajoo}

Division of Gastroenterology and Hepatology, New York Presbyterian Hospital, Weill Cornell Medical College, New York, New York, USA

\section{References}

1 Kim HJ, Park JY, Bang S et al. Self-expandable metal stents for recurrent malignant obstruction after gastric surgery. Hepatogastroenterology 2009; 56: 914-917

2 Turkyilmaz A, Eroglu A, Aydin Yet al. Complications of metallic stent placement in malignant esophageal stricture and their management. Surg Laparosc Endosc Percutan Tech 2010; 20: 10-15

\section{Bibliography}

DOI $10.1055 / \mathrm{s}-0030-1255603$

Endoscopy 2010; 42: E245 -E246

(c) Georg Thieme Verlag KG Stuttgart · New York . ISSN 0013-726X

\section{Corresponding author}

\section{B. Shah, MD}

Division of Gastroenterology and Hepatology, New York Presbyterian Hospital,

Weill Cornell Medical College, New York 1305 York Avenue

4th Floor

New York

NY 10021

USA

Fax: +1-646-962-0399

mas9217@nyp.org 